\title{
The diamondiferous Conglomerates of the Leadbetter Project, Ontario, Canada
}

\author{
J. Ryder (1), C. Verley (2), A. Miller (3), B. Martel (4) and R. Khoun (5) \\ (1)Dianor Resources, 649 3rd Avenue, 2nd floor, Val d'Or, QC, J9P 1S7, Canada (info@dianor.com) \\ (2) Amerlin Exploration Services Ltd., 2150-1851 Savage Road, Richmond, BC, V6V 1R1, Canada \\ (cverley@telus.net) \\ (3) Miller and Associates, 87 Findlay Avenue, Ottawa, ON, K1S 2V1, Canada \\ (4) B.O.Martel Inc., 5500 Chemin Chambly, Saint-Hubert, QC, J3Y 3P3, Canada \\ (5) Tara Geoscience, RR\#2, Kaministiquia, ON, P0T 1X0, Canada (tarageoscience@khoun.net)
}

The Leadbetter Diamond Project is the most advanced project of Dianor Resources and is located $12 \mathrm{~km}$ northeast of the town of Wawa in Northern Ontario, in the southern part of the Superior craton.

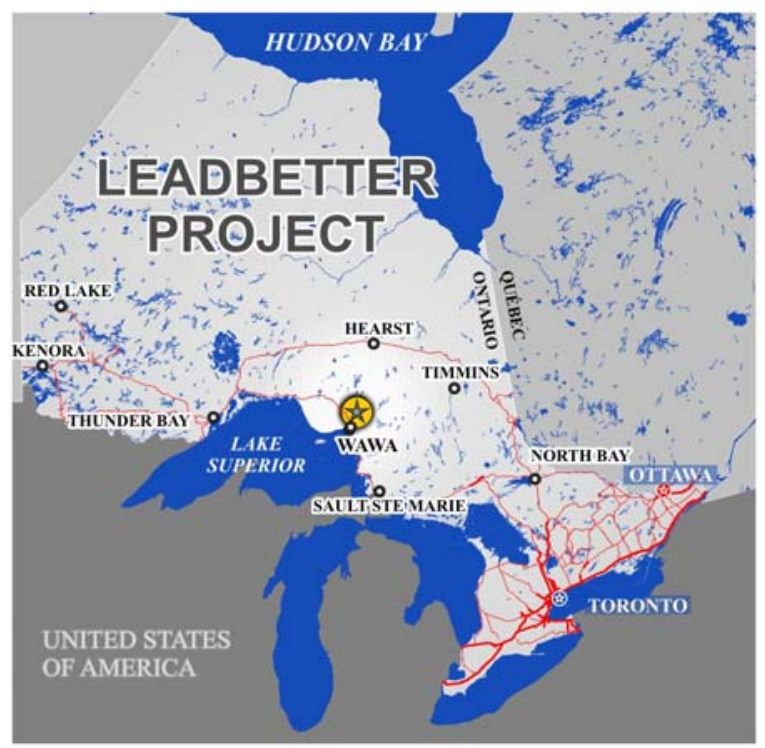

Fig. 1: Location of the Leadbetter Diamond Project.

It comprises 1590 hectares and as there is excellent infrastructure, good access and a well-trained, competent work force mine development will be low cost.

The Superior craton is one of the largest Archean age blocks and forms the old stable continental nucleus around which younger terranes have been accreted. The craton is made up of a series of volcanosedimentary terranes that amalgamated in early Proterozoic times and were then deformed and intruded during the Proterozoic by granitic batholiths. The Leadbetter Project is situated in the Michipicoten Greenstone Belt, one of the Archean volcanosedimentary belts within the Superior Craton.

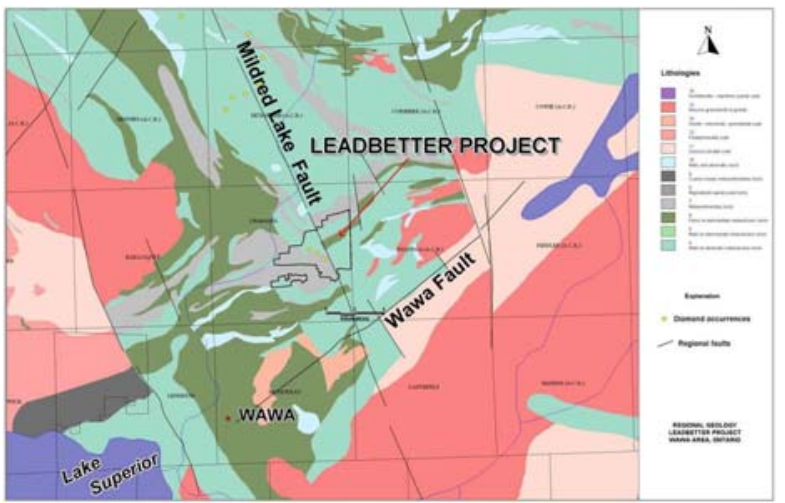

Fig. 2: Regional geological setting of the Leadbetter Project.

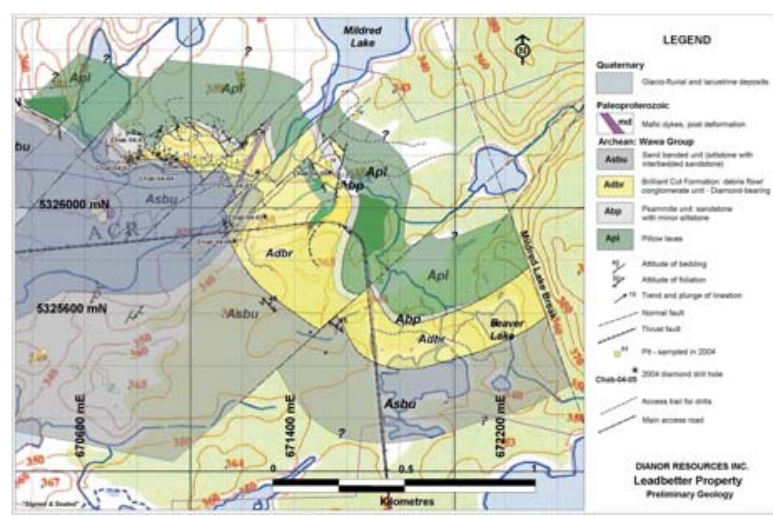

Fig. 3: Preliminary Geology of the Leadbetter Project

Diamonds were discovered in an outcropping conglomeratic unit by a prospector - Mr. Joe Leadbetter - in 2004. Reconnaissance diamond drilling of the entire Leadbetter conglomerate has enabled the preliminary subdivision of it into 3 units: a basal, mixed volcanic, volcaniclastic, conglomeratic unit (S1CV), the main Leadbetter diamond-bearing conglomerate (S1C) and an overlying conglomerate (S1CO). Diamonds have been recovered from all 3 units. The deposit model currently proposed is that of an Archean debris flow proximal to a diamond source rock. 


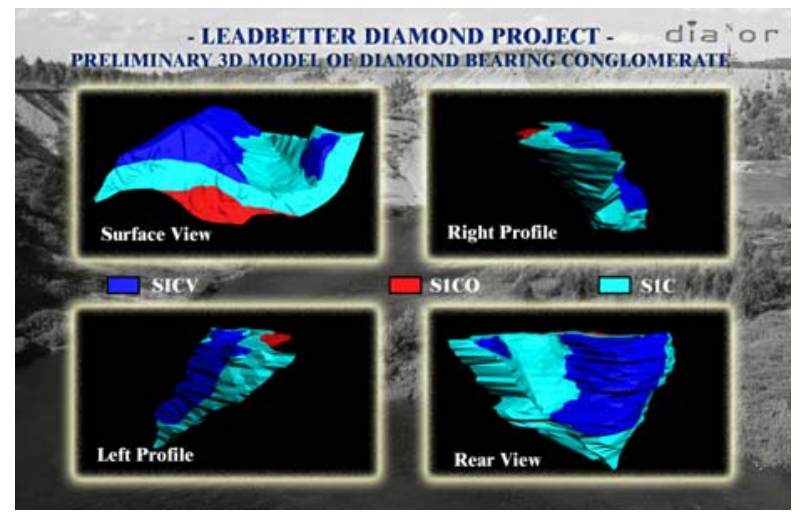

Fig. 4: Preliminary 3D Model of Conglomerate

Core drilling of a total of 146 holes has allowed a preliminary estimate of the tonnage of the diamondiferous conglomerates to be inferred. The results of this work indicate that the combined conglomerate units are in the order of 566,000,000 +/$17,000,000$ tonnes. The main diamond-bearing conglomerate (S1C) is in the order of $366,000,000$ tonnes. The preliminary tonnages estimated for the other conglomerate horizons are: 101,000,000 and 99,000,000 for S1CO and S1CV respectively.

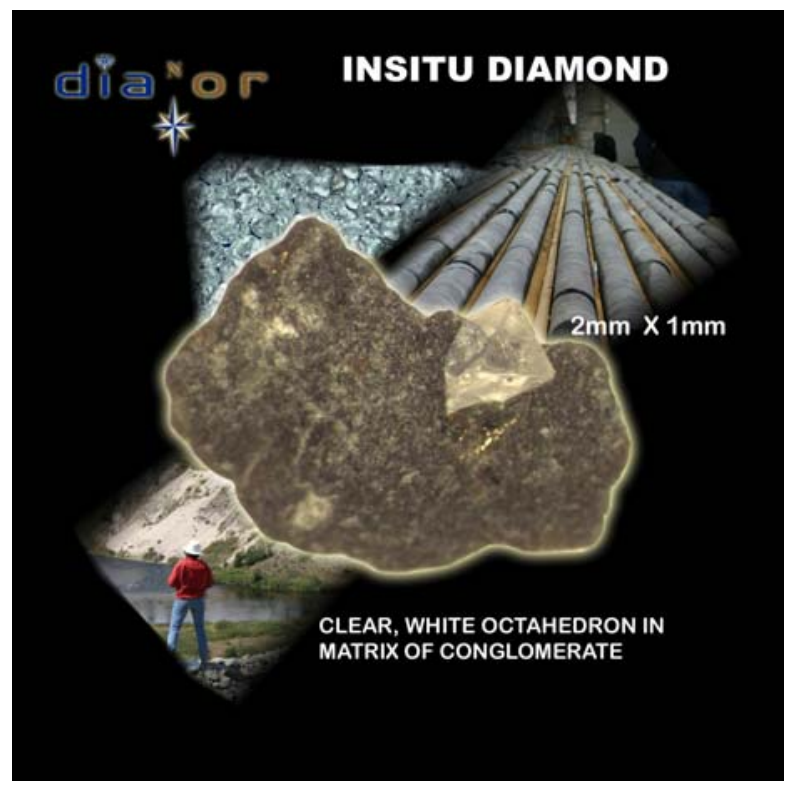

Most, if not all, diamonds reside in the matrix.

The results of diamond recovery by caustic fusion from drill core combined with preliminary diamond recovery by DMS techniques from surface samples have been used to estimate and predict, based on probability models, a range of grades for limited sets of data over parts of the known deposit. For the North Sector the preliminary grade forecast range from 0.19 to 0.29 carats per tonne. For the Central Sector grade forecasts are lower, ranging from 0.11 to 0.17 carats per tonne. No data was available to make a forecast for the South Sector. The analysis did not take into account high diamond counts internal to the conglomerate horizons, but averaged results over the entire widths of diamondiferous conglomerate.
Results of recent DMS work demonstrated that diamonds up to 1.522 carats occur in the conglomerate in the North Sector. The diamond population appears to be predominantly gem and near gem material.

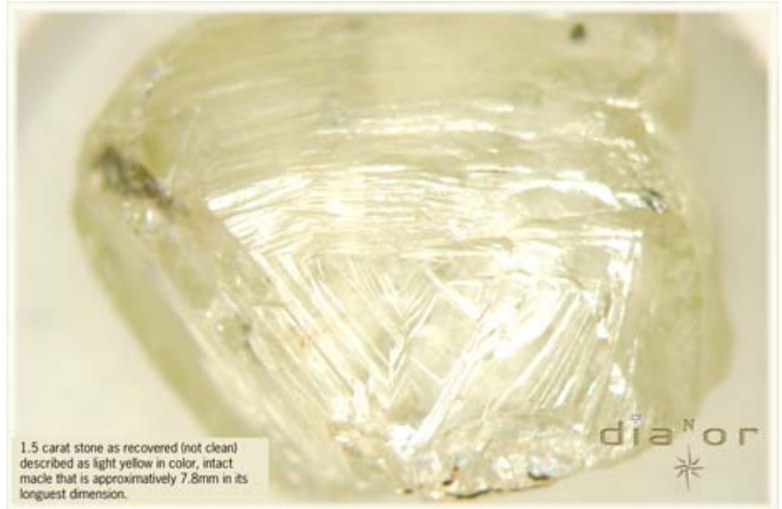

Diamonds recovered from the initial due diligence caustic fusion work indicate that $63 \%$ are white in colour, $16 \%$ yellow, $10 \%$ amber and $11 \%$ a mix of other colours.
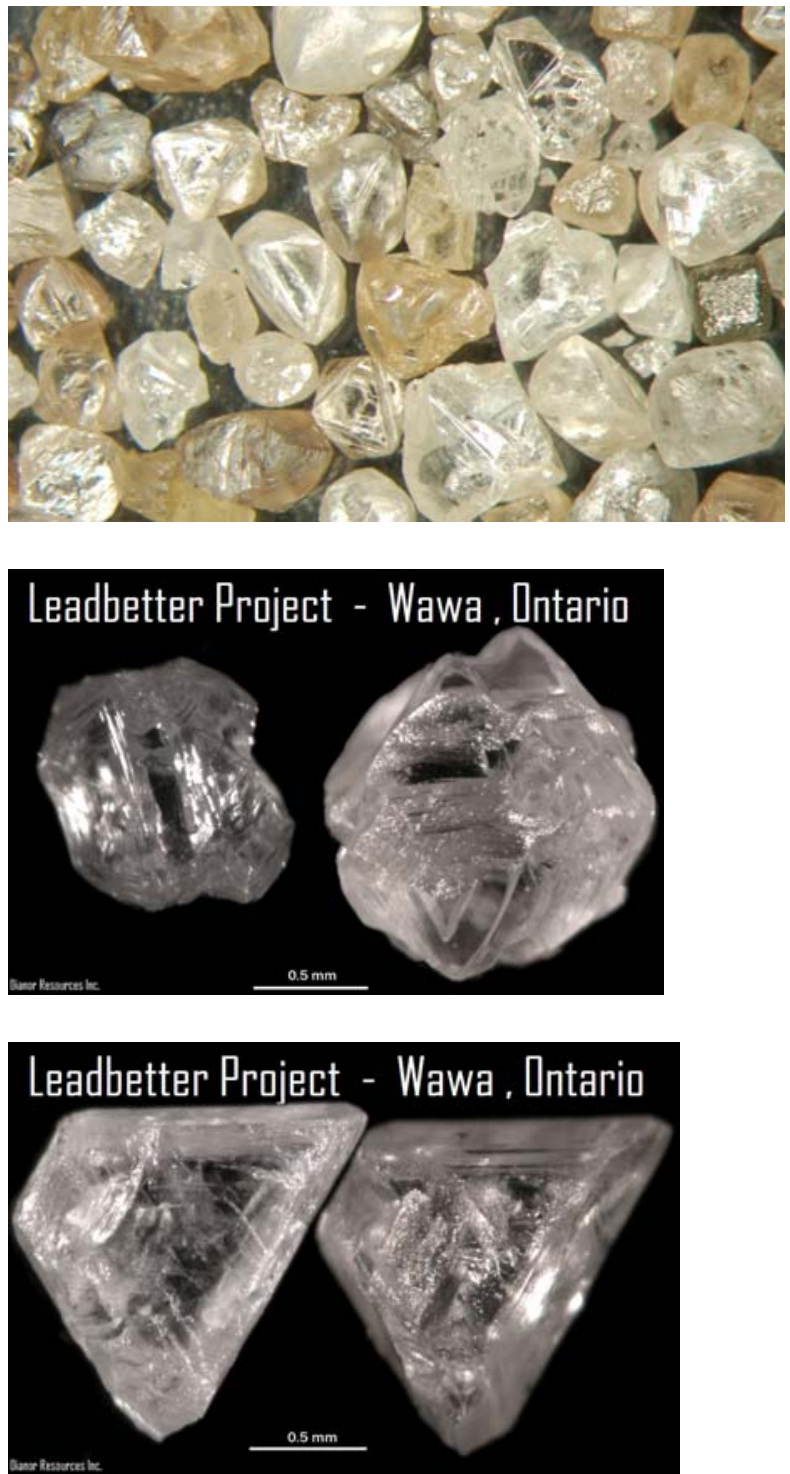


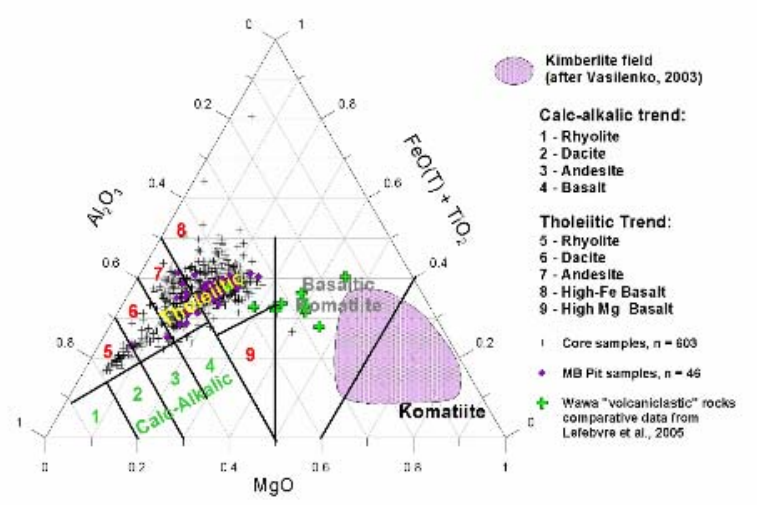

Fig. 5: Jensen Volcanic Discrimination Plot

Results from 603 whole rock analyses of drill core from conglomerate intersected in 18 drill holes and 46 test pits in the North Sector when plotted on a Jensen volcanic discrimination diagram exhibit a pronounced tholeiitic trend with the bulk of samples being of andesitic to basaltic composition. This is consistent with the clast composition observed in the conglomerate and clearly reflects the volcanic source terrain underlying the conglomerates, but it is not consistent with conventional diamond host rocks such as kimberlite, and probably does not reflect the composition of the protolith that diamonds in the Leadbetter conglomerate were derived from. The composition of the Leadbetter conglomerates is distinct from those of the diamond-bearing "Wawa volcaniclastic rocks" located to the north of the Leadbetter property. This supports the notion that the diamonds in the Leadbetter conglomerate have a unique and different source compared to the postulated source for those diamonds recovered from the Wawa volcaniclastic.

A distinct suite of kimberlitic indicator minerals was recovered, which is the main exploration technique in the glaciated terrain of Canada.

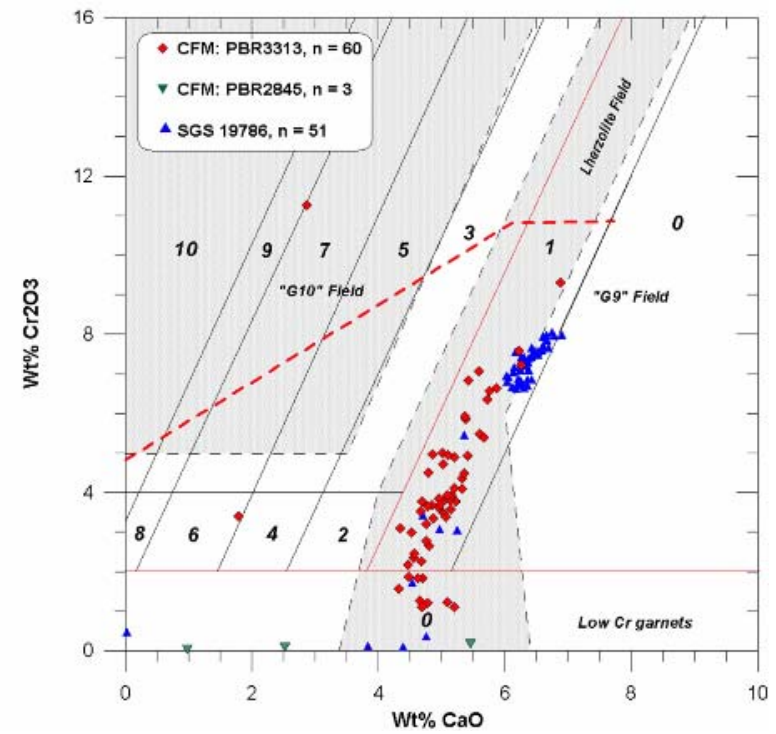

G11 or high Ti peridotite garnets, G10 or

harzburgite/dunite subcalcic garnets and mostly G9 or lherzolite, Ca-saturated garnets were recovered, as well as some G3 eclogitic garnets.
Kelyphitic rims and sub-kelyphitic orange peel and frosted textures in pyropes, adhering kimberlite material to chromediopsides and ilmenites as well as vesicular surfaces on chromites demonstrate a short transport distance and the closeness of the kimberlitic source.

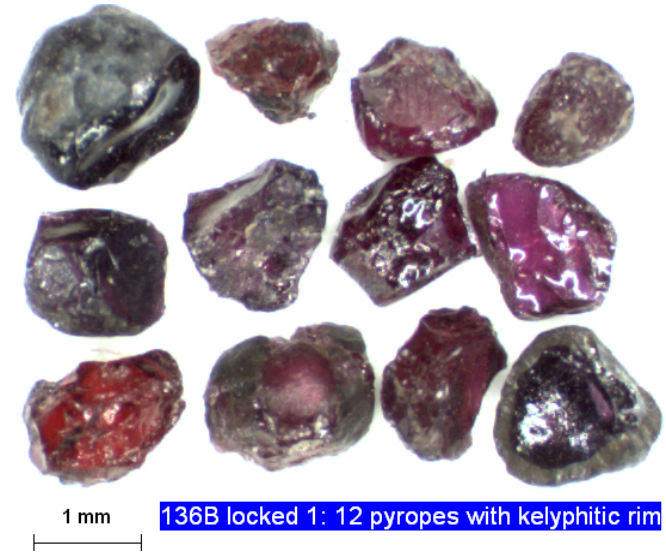

The diamond preservation potential based on the chemistry of ilmenite grains recovered from the Leadbetter conglomerates is quite high.

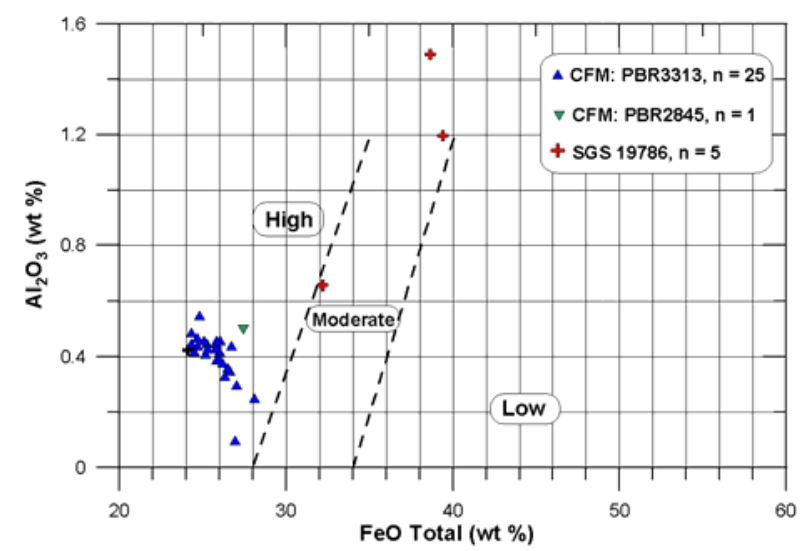

The diamondiferous conglomerates of the Leadbetter Project are a unique deposit that in addition to diamonds it contains gold (up to 9.01 grams per tonne were fire assayed), and gem-quality rubies and sapphires. It is also among the oldest in the world being dated at 2.697 billion years.

Recently Archean-aged diamond bearing conglomerates were discovered in various geographic areas of Quebec and coloured stones like pink and even very rare purple diamonds were recovered.

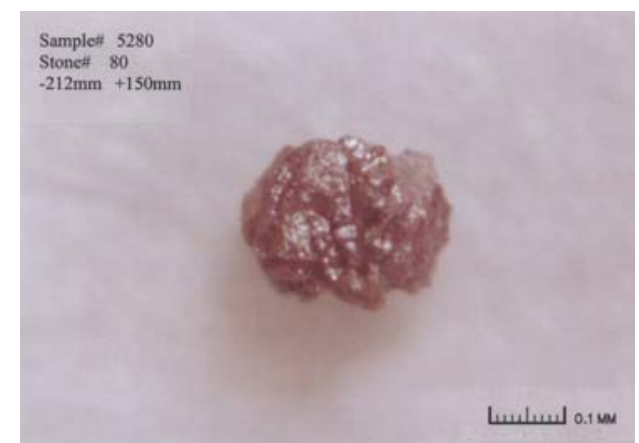

